\title{
Clínica da Exclusão: a construção do fantasma e o sujeito adolescente
}

\section{Magali Milene Silva}

Doutoranda em Psicanálise na Universidade do Estado do Rio de Janeiro- UERJ, Rio de Janeiro, RJ, Brasil

\section{Sônia Altoé}

Professora do Departamento de Psicologia da Universidade do Estado do Rio de Janeiro- UERJ, Rio de Janeiro, RJ, Brasil

\section{CLÍ NICA DA EXCLUSÃO: A CONSTRUÇÃO DO FANTASMA E 0 SUJ EI TO ADOLESCENTE (264p.) POLI , Maria Cristina}

São Paulo: Casa do Psicólogo, 2005.

O livro baseia-se em tese de doutoramento em psicologia pela Université de Paris 13, sob orientação de Jean-Jacques Rassial. Parte da experiência da autora em trabalho clínico com adolescentes internos em uma instituição pública brasileira de acolhimento de jovens afastados de suas famílias e dos questionamentos que sua prática suscitou. Objetiva estudar a particularidade da construção subjetiva na adolescência, marcada pela característica de saída da família e entrada em instituição estatal. Visa, portanto, contrastar duas situações singulares: a construção subjetiva na adolescência, concebida como momento da constituição do sinthoma, e o papel da situação social nesse processo, especificamente no caso de instituições de abrigagem.

O texto divide-se em três capítulos, ao final dos quais são discutidos casos clínicos emblemáticos das questões teóricas apresentadas no capítulo. O primeiro capítulo, intitulado "A psicanálise, a exclusão e - mal-estar", visa situar a relação entre clínica social e clínica individual para a psicanálise, a partir de Freud e Lacan, tentando esclarecer em que sentido se pode falar de uma clínica do laço social e o que significa uma clínica nomeada da exclusão.

A base de análise desse capítulo e implicitamente de todo o livro é $O$ mal estar na cultura, de Freud. É instigante acompanhar a rica extração que a autora realiza desse texto, radicalizando algumas de suas proposições principais e construindo, nesse processo, uma base sólida para se pensar a especificidade da clínica do adolescente 
morador de instituições de abrigagem. No texto, Freud considera que a cultura passa por um processo análogo ao indivíduo em relação ao manejo das pulsões. Na análise da cultura, procura estabelecer uma diferenciação entre as particularidades das sociedades e uma constante nas diversas organizações sociais, nomeando essa constante como 'elemento cultural'.

A autora sugere a aproximação entre 'elemento cultural', tal como proposto por Freud, e traço unário, tal como proposto por Lacan a partir da leitura de Psicologia de grupo. Neste texto, o ideal do eu encarnado pelo líder pode ser entendido como retorno do momento fundador da cultura, presentificação do pai da horda primitiva. O trabalho de formação de laço social, por outro lado, pressupõe o deslocamento do ideal pela rede significante, ao invés de sua cristalização numa figura. Poli propõe uma diferenciação entre sociedade e cultura. Cultura remeteria ao momento mítico de fundação, seria a oferta de uma fetichização que permite uma identificação ao pai da horda, negando a castração. É a positivação do traço ideal, como acontece com as massas e o líder. Já a sociedade seria correlata do momento de constituição da Lei que regula a relação entre os irmãos, oferecendo o objeto ideal como ausente. É nesse sentido que a autora pode afirmar que a sociedade conduz à neurose, enquanto a cultura conduz à perversão. A cultura produziria perversão porque o traço se apresenta nela positivado como fetiche enquanto na organização neurótica da sociedade, a interdição provoca uma cisão entre objeto e representação, apresentando o traço como falta. No entanto, tanto o modo perverso quanto o modo neurótico de condução, tanto a cultura quanto a sociedade, são constitutivos de nosso aparato coletivo.

Pela via da perversão da cultura a satisfação é possível, pela via da neurose do laço social ela é restrita. A relação pela via da perversão da cultura conduz a tomar o outro (próximo) ou como colaborador da satisfação sexual ou como rival (ambivalência presente em todas as análises freudianas do pai). O elemento cultural revela a face do outro na qual ele não é meu semelhante, revela a diferença radical que escapa ao espelho. É no sentido do laço social que se pode pensar a relação entre os semelhantes, unidos em relação a uma interdição externa. Há uma ilusão compartilhada de bem comum, o que se dá através do registro fálico.

Os neuróticos e as relações sociais partilhariam o mesmo tipo de estrutura fantasmática, organizando-se em torno de um ideal fálico representante do pai morto e do objeto interditado (corpo materno), enquanto 0 'elemento cultural' permaneceria insubsumível à organização fálica.

Essa dupla inscrição da coletividade permite pensar a dupla exclusão que 0 adolescente morador de instituições de abrigagem enfrenta, sob o registro da cultura, encontrando dificuldades na elaboração do 
laço social. Segundo a autora, eles carregam uma dupla bandeira de exclusão como figuras de exceção: identificados ao falo, como aqueles que estão fora da norma edípica; ou como dejeto, excluídos do princípio fálico.

O caso clínico apresentado ao final do primeiro capítulo situa a dificuldade de uma adolescente de fazer luto de suas perdas, elaborando uma construção fantasmática que the permitisse sustentação no laço social; dificuldades em ultrapassar sua identificação com o objeto fálico na forma de dejeto, em ultrapassar o registro da perversão da cultura. Vale citar sua síntese desse impasse: "por um lado a adolescência se apresenta como uma particular posição do sujeito em ruptura com este circuito de gozo, por outro lado, os adolescentes são demandados a reinstalar 0 circuito pela reafirmação da ordem fálica. O que rege aí é o princípio da normopatia. Na especificidade de adolescentes que se situam como 'fora da norma' - como são concebidos no discurso os adolescentes em instituição - o paradoxismo da demanda social se expressa de forma radical, desnudando o princípio de exclusão que norteia o funcionamento do discurso" (p.248).

O segundo capítulo, "Alienação, separação, exclusão: de Freud a Lacan", propõe-se a demonstrar que o lugar de exclusão social refere-se a elevado grau de alienação, tal como apresentado por Lacan. Discute, por conseguinte, as operações de alienação e separação e os impasses desses momentos para o sujeito adolescente.

Não há em Freud um emprego conceitual do termo alienação, no entanto, a fim de compreender o modo como Lacan considera a alienação, a autora considera fundamental remeter-se às elaborações freudianas acerca da complexa relação entre 'mundo externo' e 'mundo interno', entre 'eu' e 'objeto'.

Tendo as intuições freudianas como pano de fundo, Poli se propõe a realizar um estudo sobre a alienação em Lacan, não sem antes fazer um percurso histórico sobre a apreensão filosófica e médica do conceito, a fim de situar em que sentido Lacan se destaca dessas concepções.

Também em Lacan, não encontramos sobre a alienação uma concepção única. A autora realiza minucioso percurso em sua obra, extraindo e discutindo as diferentes concepções do termo, chegando ao modo como é elaborado em relação à separação. Essa análise interessa especialmente à discussão dos casos apresentados, pois propõe alienação e separação como processos da construção estrutural que situam um lugar para o sujeito.

O caso apresentado nesse capítulo mostra a dificuldade de uma adolescente em se separar de sua mãe, uma vez que a adolescência é concebida no contexto de modificação nas condições de alienação e separação do sujeito. O adolescente é convocado a confrontar-se com 
- Outro sexo e a tentar uma forma de circunscrever esse enigma para além da lógica fálica, passagem da família ao laço social. Diante dessa tarefa, os adolescentes habitantes de instituição, identificados como figuras de exceção, devem encontrar um lugar para si para além dessa nomeação social, deve conseguir uma voz própria, ultrapassando o modo como é falado; processo que, muitas vezes, é dificultado pela estrutura das instituições.

O terceiro e último capítulo, "Mito de origem e fantasma originário na psicopatologia da adolescência na clínica do laço social", a partir da base conceitual dos capítulos anteriores, discute a especificidade da construção do fantasma na adolescência e os impasses que a institucionalização evoca nesse momento.

Trata-se em uma análise de evocar uma narrativa, mas a análise não visa apenas a história, mas o lugar do sujeito nessa história, ao mesmo tempo seu autor e seu produto.

Desde o início de seu trabalho, Freud faz referência a fantasias originárias, destacando a cena primária, a fantasia de sedução e a fantasia de castração. As fantasias são modos como a criança responde aos enigmas da origem e da diferença sexual. Elas respondem à urgência de uma construção psíquica que abarque 0 hiato em que a linguagem se funda, hiato entre real e representação. Lacan propõe que o recalque originário é efeito da produção de sentido, do movimento de alienação, da captura do sujeito no campo do Outro. Já a separação diria respeito ao movimento de retorno do recalcado, ao S1 que retorna como enigma. Nesse processo, Das Ding é o elemento perdido pela incidência do recalque originário. Lacan evoca nessa operação o caráter de Outro primordial de Das Ding, destacando sua ambigüidade: ao mesmo tempo objeto de referência e de incesto, fonte de horror e perdição do sujeito - inscrição de um ato originário e sua proibição.

Trata-se, no que chamamos de clínica do social, de interrogar quais os efeitos das precondições do Outro no lugar que o sujeito ocupa em sua narrativa particular. Ao contar sua história, o paciente põe-se a produzir, mas também a reproduzir o modo como é contado. A especificidade de vida dos adolescentes em instituição de abrigagem comporta algumas particularidades na produção dessa narrativa. Elas se devem não somente ao universo culturalmente empobrecido em que vivem, mas à mudança de referência em relação ao afastamento da família, somados ao momento de vida, a adolescência.

A autora relata dificuldades desses pacientes em construir uma narrativa, respondendo com certo mal-estar ao serem argüidos sobre sua história. Quando se narram, muitas vezes repetem o discurso técnico sobre eles, apresentando bastante dificuldade na articulação de uma narrativa que inclua o sujeito.

Comentando o livro Abandonarás teu pai e tua mãe, de Julien, Poli propõe que na modernidade ocorre uma separação entre 
conjugalidade e parentalidade, ficando a primeira no domínio privado, enquanto a segunda no domínio público. Desse modo, a responsabilidade pela criança é cada vez menos dos pais e mais de instituições, recheadas de peritos que devem julgar o melhor para a criança. Assim, as crianças que estão em instituição têm comprovada a falência de seu ambiente familiar. Cabe considerar, ainda, que as questões de filiação são fundamentais não apenas jurídica e socialmente, mas enquanto material de apoio para as construções fantasmáticas.

É preciso perguntar novamente qual o papel das instituições nessa construção.

Desde que Lacan realizou sua crítica do drama edípico a questão da família parte da diferença de posição da mãe e do pai em relação à criança, mas a dificuldade está em precisar a importância da passagem da função ao personagem, especificamente no que diz respeito ao lugar do pai. Há certo consenso em relação à importância da presença da mãe, da relação materna primordial, que não pode dispensar o elemento corporal. Já o pai, como função simbólica, tem acesso, sobretudo, por intermédio da palavra da mãe. É claro que não se trata da idealização de um modelo de família, mas de não recuar ante a necessidade de discutir o papel do personagem real nas funções paterna e materna, conforme a autora apontará a respeito da função do tu na constituição do sujeito. "A nossa hipótese é que a construção de uma narrativa ficcional no lugar do puro exercício da lógica fálica é o elemento necessário para o apaziguamento do sadismo superegóico. Isso implica, necessariamente, em não fazer a economia de uma certa fetichização da função do pai, mas de relativizá-la pela multiplicidade de versões, de pere-versions" (p.196).

As instituições de abrigagem, sob a bandeira do bem-estar, agem sob a vigência radical do princípio fálico, pautadas pela moralidade superegóica, ordenadas pelo discurso da ciência. Agem, portanto, com vistas a um ideal normalizador, rejeitando a diferença, constituindo-se, muitas vezes, como instituições totais ou, ao menos, aspirando a tal.

A autora propõe denominar família como suporte real, simbólico e imaginário que um indivíduo (ou mais) dá ao outro para realização singular de sua operação de alienação/separação. Destaca a importância da relação subjetiva, da presença de um eu e de um tu reais para que a transmissão do desejo se dê.

A função desse tu é de autenticador do discurso, mediador entre o sujeito e o Outro como puro significante, tornando o encontro com o Outro suportável e passível de construção subjetiva. É preciso que o semelhante seja suporte do furo estrutural engendrado pela constituição do universo discursivo (recalcamento originário). O outro é, pois, suporte para a transmissão do Nome-do-Pai. 
O que está em jogo na constituição do Nome-do-pai é a possibilidade de uma nominação originária, de uma autenticação singular do Nome-do-Pai. O psicótico encontra dificuldades nessa nomeação. $O$ neurótico o faz, mas fica preso à fixidez da versão que constrói com seu fantasma. Fazer uma pere-version como propôs Lacan implica uma "apropriação dos significantes que o discurso the oferece sem precisar pagar o preço da alienação fantasmática ao gozo do Outro" (p.209). A adolescência é o momento em que é possível retomar os fantasmas infantis, quer refixando-se a eles, quer construindo uma pere-version.

Concordando com Rassial, Poli situa a adolescência como momento da operação do sinthoma. A narrativa das origens revela o lugar do sujeito nessa operação. A narrativa das origens não é nem individual nem social, mas o seu ponto singular de encontro. Diz respeito ao modo como cada sujeito vai dar conta daquilo que o precede e ao qual ele eksiste. Trata-se da construção ficcional de um eu narrador, onde podemos reconhecer a incidência dos processos de alienação e separação.

Na infância, o sujeito encontra nas teorias sexuais uma resposta aos enigmas da origem, sendo estas teorias suportadas na cultura por uma representação coletivamente partilhada de cena primária. A autora propõe que cena primária e teoria sexual infantil, são versões do mesmo movimento, mas na primeira o sujeito se encontraria completamente alienado a seu lugar na estrutura, enquanto na segunda há separação. Ao chegar à puberdade, a confrontação com o real do corpo, levanta novos enigmas sobre o Outro sexo que o sujeito deverá re-encaminhar. Uma construção que se serve da organização fálica, mas pode ultrapassá-la. Essa tarefa não é simples nem rapidamente concluída. A noção lacaniana de sinthoma evoca algo dessa construção, uma possibilidade de "propor uma versão da realidade que altere as próprias condições de representação" (p.229). Os casos apresentados nesse capítulo mostram possibilidades e dificuldades de adolescentes nesse processo.

A conclusão do trabalho é magistral: Uma narrativa ou a vida. Com esse título, retirado de uma análise de Todorov sobre as Mil e uma noites, a autora situa muito bem o drama dos adolescentes moradores de instituições: no despedaçamento de suas histórias eles devem localizar um fio, ponto de onde eles possam narrá-las, construindo-se como sujeitos. Sua conclusão me conduziu a considerar que o papel do analista é evocar essa tecelagem, para que cada um possa encontrar seu fio de Ariadne, mesmo que o sujeito, como Penélope, precise desmanchar muitas vezes. 


\section{Referências Bibliográficas}

POLI, Maria Cristina. Clínica da Exclusão: a construção do fantasma e o sujeito adolescente. São Paulo: Casa do Psicólogo, 2005.

\section{Endereço para correspondência}

Magali Milene Silva

Pós-graduação em Psicanálise, Universidade do Estado do Rio de Janeiro- UERJ, Rua São Francisco Xavier, 524, $10^{\circ}$ andar Bloco B, Sala 10.015, Maracanã, CEP 20550-900, Rio de Janeiro, RJ, Brasil

Endereço eletrônico: magalimilene@gmail.com

Sônia Altoé

Psicologia Jurídica, Universidade do Estado do Rio de Janeiro - UERJ, Rua São Francisco Xavier, 524, $10^{\circ}$ andar Bloco B, Sala 10.015, Maracanã, CEP 20550-900, Rio de Janeiro, RJ, Brasil

Endereço eletrônico: sonia.altoe@terra.com.br

Recebido em: 09/10/2008

Aceito para publicação em: 06/03/2009

Acompanhamento do processo editorial: Eleonôra Prestrelo e Anna Uziel 